\title{
Application of Globin and Keto-hexose Glycated Globin to Wheat-based Products
}

\author{
Innun, A., Hayakawa, S., Ogawa, M. and Gohtani, S.
}

Department of Biochemistry and Food Science, Kagawa University, Ikenobe, Miki, Kagawa, 761-0795 Japan, s06x606@stmail.ag.kagawa-u.ac.jp

\begin{abstract}
Globin $(\mathrm{Gb})$, an abundant protein in animal blood, is a rich source of essential amino acids, esp. lysine, and possesses various functional properties. In this study, Gb and Gb-sugar conjugates were applied to the production of bread and pasta. Gb-sugar conjugate was prepared by glycating hemoglobin with keto-hexose sugars (fructose and psicose) through Maillard reaction in dry state at $40{ }^{\circ} \mathrm{C}$ and $60 \%$ humidity for $24 \mathrm{~h}$. The effects of $\mathrm{Gb}$ and glycated Gbs on rheological properties of dough were determined by Farinograph and Rheogel and on finished products by Creep meter. The addition of $\mathrm{Gb}$ and glycated Gbs to wheat flour pronouncedly improved rheological properties both of bread and pasta dough as compared to the control. In finished products, the addition of $\mathrm{Gb}$ and glycated $\mathrm{Gbs}$ showed different effect on the textural characteristics of bread and pasta. Bread formulated with glycated Gbs were more elastic, softer and larger than that formulated with Gb while pasta formulated with $\mathrm{Gb}$ exhibited stronger structure and more resistant to deformation than that formulated with glycated Gbs. These results suggest that the benefit of applying Gb or glycated Gbs to wheat-based products depends on the textural characteristics of finished products.
\end{abstract}

Keywords: Bread, dough, globin, Maillard reaction, pasta

\section{Introduction}

Animal blood is produced in a massive amount from slaughterhouse. Although animal blood has been succeeded to incorporate in blood sausage which is available on the market in many countries, only a small amount of blood has been taken for this purpose. Most of it has been utilized mainly in animal feeds. Hemoglobin $(\mathrm{Hb})$ is primary protein in blood. Considering in term of food application, $\mathrm{Hb}$ requires further processing of decolorization to remove its dark red color and odor (Dill and Landmann, 1988). A colorless protein named "globin" $(\mathrm{Gb})$ is regularly obtained after decolorization process of $\mathrm{Hb}$. $\mathrm{Gb}$ possesses various functional properties, such as, foaming, emulsifying, gelling and water-holding capacity (Gómez-Juárez et al., 1999; Shahidi et al., 1984; Hayakawa et al., 1982; Wismer-Perderson, 1979). Moreover, a large amount of essential amino acids, in particular lysine, is contained in Gb (Dill and Landmann, 1988; Tybor et al., 1975; Duarte et al., 1999; Márquez et al., 2005). Therefore, $\mathrm{Gb}$ would be beneficial to some food products which are low in lysine level. Since wheat flour is low in lysine content, the addition of $\mathrm{Gb}$ to wheat flour could be a lysine supplement.

Maillard reaction, non-enzymatic interaction between carbonyl group of reducing sugar and free amino group of protein or amino acid, results in the generation of aroma, color and flavor in many food products. In particular, this reaction has been employed to improve some functional, chemical and/or antioxidant properties of proteins (Aoki et al., 1999, Sun 
et al., 2004, Benjakul et al., 2005, Sun et al., 2004, 2006, Yilmaz and Toledo, 2005). The objective of this study was to utilize $\mathrm{Gb}$ in the production of bread and pasta and also to take the advantage of Maillard reaction to improve functional properties of $\mathrm{Gb}$ by modifying Gb with keto-hexose sugars (D-fructose and D-psicose).

\section{Materials and Methods}

Bovine $\mathrm{Hb}$ for bread-making was purchased from Sigma Chemical Co. (Mo, USA) and porcine $\mathrm{Hb}$ for pasta-making was prepared from porcine blood. D-fructose (Fru) was purchased from Wako Pure Chem. Ind., Ltd. (Osaka, Japan). D-psicose (Psi) was obtained from Kagawa Rare Sugar Cluster (Kagawa, Japan). Wheat flour for bread dough measurement (by Farinograph) was a commercial "Haruyokoi" (Yokoyama Milling Co., Hokkaido, Japan) and that for bread-making was "Kameriya" (Nissin Flour Milling Co., Tokyo, Japan). Wheat flour for pasta-making was a mixture of durum semolina and farina (Cuoca Planning Co., Ltd., Tokushima, Japan).

Preparation of Hb-sugar complexes

$\mathrm{Hb}$-sugar complexes were prepared by glycating $\mathrm{Hb}$ with sugars (Fru and Psi) via Maillard reaction. $\mathrm{Hb}(5 \mathrm{~g})$ was mixed with each sugar $(0.7 \mathrm{~g})$ in $100 \mathrm{ml}$ of $10 \mathrm{mM}$ sodium phosphate buffer ( $\mathrm{pH}$ 7.2). The mixed solution was lyophilized. The powdered mixture was incubated at $40{ }^{\circ} \mathrm{C}$ and $60 \%$ relative humidity for $24 \mathrm{~h}$ under dry state condition.

Preparation of $G b$ and $G b$-sugar complexes

$\mathrm{Gb}$ and $\mathrm{Gb}$-sugar complexes were prepared from $\mathrm{Hb}$ and $\mathrm{Hb}$-sugar complexes, respectively by soluble carboxymethyl cellulose (CMC) method (Hayakawa et al., 1986).

Preparation of bread

Bread containing $\mathrm{Gb}$ or $\mathrm{Gb}$-sugar complex was prepared using the following ingredients; wheat flour (300 g), shortening (20 g), sugar (10 g), salt ( $0.5 \mathrm{~g})$, dry yeast ( $3 \mathrm{~g}$, suspended in $20 \mathrm{ml}$ water) and $150 \mathrm{ml}$ of $2 \%(\mathrm{w} / \mathrm{v}) \mathrm{Gb}$ or glycated Gbs solutions. The ingredients were mixed and kneaded. The resulting dough was incubated, sheeted, molded and proofed. Finally, the proofed dough was baked for $35 \mathrm{~min}$ in a bakery oven set at $190{ }^{\circ} \mathrm{C}$. Control bread also was prepared with the same manner except for adding $150 \mathrm{ml}$ of water instead of protein sample solution.

\section{Preparation of pasta noodle}

Pasta containing $\mathrm{Gb}$ or $\mathrm{Gb}$-sugar complex was prepared from the mixed flour of durum semolina and farina $(1: 1, \mathrm{w} / \mathrm{w})$, and $4 \%$ Gb or glycated Gbs solution using a home pasta maker (Imperia SP-150, Italy). Firstly, two hundred grams of the mixing flour were mixed with $90 \mathrm{ml}$ of 4\% protein sample solution and kneaded using a mixer (Hitachi HM-160, Japan). The kneaded dough was sheeted and cut in pieces as pasta with a site of approximately $1.7 \mathrm{~mm}$ thick, $6.5 \mathrm{~mm}$ wide and $5 \mathrm{~cm}$ long. The control pasta was also prepared with the same manner except replacing protein solution with distilled water in the same volume. 


\section{Determination of rheological properties of bread and pasta dough}

Farinograph (DO-CORDER E 330, Germany) was used to determine water absorption of flour and rheological properties of dough. Three hundred grams of bread wheat flour were mixed in a mixing chamber of instrument and $2 \%(\mathrm{w} / \mathrm{v})$ of protein samples solution was added to the pre-mixed flour until consistency of mixing dough reached to 500 Brabender Units (BU). The measurement was carried out at a constant speed of $63 \mathrm{rpm}$ and at $30^{\circ} \mathrm{C}$.

Dynamic properties of pasta dough were determined using Rheogel-E4000 (UBM Co., Ltd., Japan) with parallel plate. Dough samples were obtained by mixing $100 \mathrm{~g}$ wheat flour (50 g durum and $50 \mathrm{~g}$ farina) with $45 \mathrm{ml}$ of $2 \%$ protein samples solution or water (control). An aliquot amount of pasta dough was fitted on the parallel plate, previously covered with silicone oil on the edge. Strain sweep test was conducted at fixed frequency of $1 \mathrm{~Hz}$ with increasing the strain amplitude. The measurements were carried out at constant temperature of $30^{\circ} \mathrm{C}$.

\section{Determination of qualities of finished bread and cooked pasta}

Qualities of bread product were evaluated after $24 \mathrm{~h}$ of cooling using Rheoner II Creep meter (RE 2-3305, Yamaden Co., Japan) with plunger area of $5 \times 5 \mathrm{~cm}^{2}$, load cell of $2 \mathrm{kgf}$. A cube of bread crumbs was compressed at a cross-head speed of $1 \mathrm{~mm} / \mathrm{sec}$ and holding time of $1 \mathrm{~min}$. The results were analyzed using the creep analysis Windows' software (Yamaden Co.) and expressed by the parameters of modulus of elasticity $\left(\mathrm{N} / \mathrm{m}^{2}\right)$ and viscosity coefficient $(\mathrm{Pa} \cdot \mathrm{s})$.

Qualities of pasta noodle after cooking for $2.5 \mathrm{~min}$ in boiling water were evaluated by Rheoner II Creep meter using a triangle shape plunger (1 mm thickness). Cooked pasta noodle was cut at speed of $0.5 \mathrm{~mm} / \mathrm{sec}$ with the plunger and load cell of $2 \mathrm{kgf}$. Every sample was measured at 5 replications; each replication was measured using 25 noodles.

\section{Statistical analysis}

Analysis of variance (ANOVA) followed by Duncan's new multiple range test were used for statistical analysis. Results from all tests were expressed by mean value.

\section{Results and Discussion}

\section{Glycation degree of Gb-sugar complexes}

In this study, MALDI-TOF mass spectrometry was used for mass determination of protein samples. The results were shown in Figure 1. The intact Gb sample showed a major peak with the mass of $15030 \mathrm{~m} / \mathrm{z}$ while Gb-sugar samples showed multiple peaks which consisted of original peak and additional peaks. Gb-Fru sample revealed three additional peaks with the mass of $\mathrm{m} / \mathrm{z} 15192,15354$ and 15516. Gb-Psi had two additional peaks with the mass of $m / z 15192$ and 15354. A mass difference of 162 Da corresponds to a hexose residue. Therefore, it could be concluded that a Gb molecule bound 1-3 molecules of Fru or 1-2 molecules of Psi, respectively.

\section{Rheological properties of bread dough}

Table 1 illustrates rheological properties of bread dough. Water absorption of dough was highest in dough containing Gb, followed by Gb-Psi, Gb-Fru and control dough (without 
$\mathrm{Gb}$ ). Water absorption is percentage of water required to yield dough consistency of 500 BU. Higher value suggests better dough quality. Therefore, the addition of $\mathrm{Gb}$ and glycated Gbs significantly improved dough quality for the water absorption compared to the control. Weakening of dough, an indicator of the consistency of dough, was improved by the addition of $\mathrm{Gb}$ and in particular glycated Gbs as compared to control dough. Stability of dough was considerably improved by the addition of glycated Gbs, although the addition of $\mathrm{Gb}$ did not affect it. In general, dough stability implies the strength of dough towards mixing. From these results, it can be concluded that the addition of glycated Gbs to wheat flour highly improved the qualities of dough.

Autio et al. (1984) demonstrated that Gb prepared using soluble CMC method exhibited high water-holding capacity. The high water-holding of $\mathrm{Gb}$, therefore, could be associated with the increase in water absorption of dough. The addition of glycated Gbs to wheat flour brought considerable improvement in weakening and stability of dough. It is probably due to the effect of sugar molecules attached to Gb-sugar complexes and/or the effect of additional Maillard reaction products (MRPs) produced from the glycation of $\mathrm{Gb}$ with sugar. Rheological properties of pasta dough

Rheological properties of pasta dough were tested using Rheogel rheometer. Figure 2 shows elastic modulus $\left(G^{\prime}\right)$ of pasta dough samples. Compared to the control, $G^{\prime}$ increased by the addition of $\mathrm{Gb}$ and slightly increased by the addition of glycated Gbs. A high value of $G^{\prime}$ indicates stiff dough, conversely, a lower $G^{\prime}$ indicates softer and more extensible dough. Compared to control pasta dough, dough containing Gb was a relatively stiff dough while that containing glycated Gbs were softer and more extensive dough. Figure 3 presents loss tangent of dough samples. Loss tangent of dough implies viscoelastic behavior of dough. All dough samples showed almost same increasing patterns of loss tangent value with increasing strain.

Rheological properties of bread dough obtained using Farinograph and of pasta dough obtained using rheometer agreed that the addition of $\mathrm{Gb}$ to wheat flour produced stronger dough. This is probably due to the strong interaction between $\mathrm{Gb}$ molecules and wheat flour proteins. This strong interaction between $\mathrm{Gb}$ and wheat flour proteins was slightly weakened when Gb was glycated with sugar.

\section{Qualities of finished bread product}

Table 2 shows the qualities of finished bread products. The addition of $\mathrm{Gb}$ revealed higher modulus of elasticity than the control (bread without $\mathrm{Gb}$ ), whereas, the addition of glycated Gbs showed no significant difference from the control. Coefficient of viscosity of bread was highest in bread formulated with Gb, followed by Gb-Fru, control and Gb-Psi. Low values of elastic modulus and viscosity coefficient imply that bread is elastic and soft. Therefore, bread formulated with glycated Gbs showed more elastic and softer than bread formulated with $\mathrm{Gb}$. The degree of softness of bread followed the order bread containing Gb-Psi $>$ control $>$ Gb-Fru $>$ Gb. Specific volume of bread formulated with glycated Gbs was apparently larger than that formulated with $\mathrm{Gb}$ and control bread. From the overall results, it can be concluded that the quality of bread was poor in bread formulated with $\mathrm{Gb}$, but it was 
getting better when the bread was formulated with glycated Gbs. These results suggested that glycating $\mathrm{Gb}$ with sugar improved functional properties of $\mathrm{Gb}$ in bread-making.

Qualities of cooked pasta

Table 3 shows the textural characteristics of cooked pasta noodle. The results clearly illustrate that the addition of $\mathrm{Gb}$ to the production of pasta significantly increased breaking stress and breaking energy of cooked pasta when compared to the control pasta. Breaking stress and breaking energy values imply the strength of pasta noodle structure being resistant to deformation. Therefore, the degree of resistance to deformation of cooked pasta noodle followed the order $\mathrm{Gb}>\mathrm{Gb}$-Fru $>\mathrm{Gb}$-Psi $>$ control pasta. Pasta containing $\mathrm{Gb}$ was the most resistant to deformation because of strong noodle structure. Although the mean values for breaking stress and breaking energy of pasta containing glycated Gbs were lower than that containing $\mathrm{Gb}$, the values were significantly higher than the control pasta. The formation of strong network in pasta noodle promoted by Gb or glycated Gbs may be associated with the heat-induced gel property of $\mathrm{Gb}$. A number of studies suggested that $\mathrm{Gb}$ formed gel after heating at temperature above $60{ }^{\circ} \mathrm{C}$ (Autio et al., 1985; Hayakawa et al., 1982).

The changes in the textural characteristics of bread and pasta products by the addition of $\mathrm{Gb}$ and glycated Gbs may be associated with their rheological properties of dough. The addition of $\mathrm{Gb}$ to wheat flour gave stronger dough, resulting in bread with more elastic and tough and pasta with high resistance to deformation. However, dough containing glycated Gbs showed weaker dough than that containing $\mathrm{Gb}$; hence producing softer bread and pasta.

\section{Conclusion}

The addition of $\mathrm{Gb}$ and glycated $\mathrm{Gbs}$ to wheat flour improved rheological properties both of bread and pasta dough as compared to the control dough. In finished product, the benefit of applying $\mathrm{Gb}$ or glycated Gbs to wheat-based products depends on the textural characteristics of finished products. In bread product which soft texture is preferred, the addition of glycated Gbs would give more benefit than the addition of Gb. On the other hand, strong structure of noodle is preferred for pasta-making, thus, the addition of Gb to production of pasta would be better than the addition of glycated Gb. Furthermore, the addition of $\mathrm{Gb}$ and glycated Gbs to the production of wheat-based products will have potential nutrition values of lysine and protein levels. 
Table 1-Rheological properties of bread dough samples analyzed by Farinograph

\begin{tabular}{lccc}
\hline Sample & Water absorption (\%) & Weakening (BU) & Stability (min) \\
\hline Control & $71.33^{\mathrm{a}}$ & $57.5^{\mathrm{c}}$ & $3.5^{\mathrm{a}}$ \\
\hline $\mathrm{Gb}$ & $75.33^{\mathrm{c}}$ & $43.3^{\mathrm{b}}$ & $3.0^{\mathrm{a}}$ \\
\hline $\mathrm{Gb}-\mathrm{Fru}$ & $74.67^{\mathrm{b}}$ & $11.7^{\mathrm{a}}$ & $>10$ \\
\hline $\mathrm{Gb}-\mathrm{Psi}$ & $74.89^{\mathrm{bc}}$ & $10.0^{\mathrm{a}}$ & $>10$ \\
\hline
\end{tabular}

The same letters in a column show not significantly different $(P>0.05, \mathrm{n}=3)$

Table 2-Qualities of finished bread products

\begin{tabular}{lccc}
\hline Sample & $\begin{array}{c}\text { Modulus of elasticity } \\
\left(\mathrm{N} / \mathrm{m}^{2} \times 10^{4}\right)\end{array}$ & $\begin{array}{c}\text { Coefficient of viscosity } \\
\left(\mathrm{Pa} \cdot \mathrm{s} \times 10^{6}\right)\end{array}$ & $\begin{array}{c}\text { Specific volume } \\
(\mathrm{ml} / \mathrm{g})\end{array}$ \\
\hline Control & $1.70^{\mathrm{a}}$ & $3.16^{\mathrm{a}}$ & 3.76 \\
\hline $\mathrm{Gb}$ & $4.10^{\mathrm{b}}$ & $8.24^{\mathrm{b}}$ & 3.50 \\
\hline $\mathrm{Gb}$-Fru & $2.14^{\mathrm{a}}$ & $4.02^{\mathrm{a}}$ & $3.99^{*}$ \\
\hline Gb-Psi & $1.61^{\mathrm{a}}$ & $2.16^{\mathrm{a}}$ & $3.94^{*}$
\end{tabular}

The same letters in a column show not significantly different $(P>0.05, \mathrm{n}=3)$

* represents significant difference from the control at the level of $P<0.05$

Table 3-Qualities of cooked pasta samples determined by Creep test

\begin{tabular}{lcc}
\hline Sample & Breaking stress $\left(\mathrm{N} / \mathrm{m}^{2} \times 10^{5}\right)$ & Breaking energy $\left(\mathrm{J} / \mathrm{m}^{3} \times 10^{5}\right)$ \\
\hline Control & $2.75^{\mathrm{a}}$ & $1.12^{\mathrm{a}}$ \\
\hline $\mathrm{Gb}$ & $3.42^{\mathrm{b}}$ & $1.37^{\mathrm{b}}$ \\
\hline Gb-Fru & $3.27^{\mathrm{b}}$ & $1.36^{\mathrm{b}}$ \\
\hline Gb-Psi & $3.17^{\mathrm{b}}$ & $1.29^{\mathrm{b}}$ \\
\hline
\end{tabular}

The same letters in a column show not significantly different $(P>0.05, \mathrm{n}=5)$ 


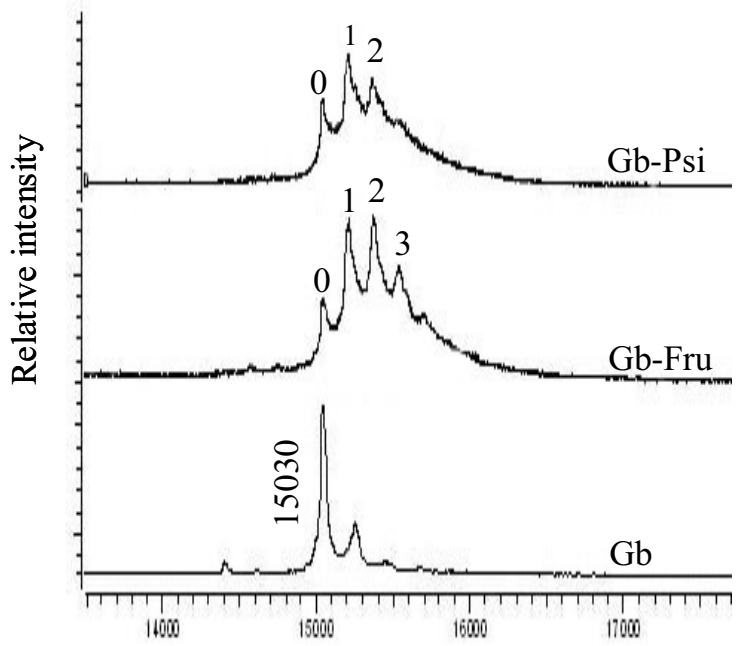

Figure 1-MALDI-TOF mass spectra of Gb and glycated Gbs

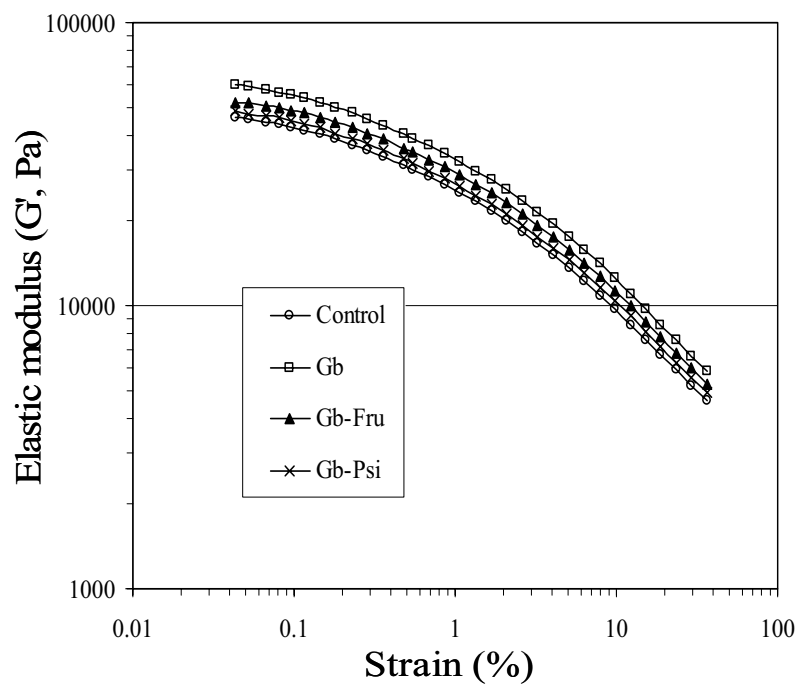

Figure 2-The effect of $\mathrm{Gb}$ and glycated $\mathrm{Gbs}$ on the storage modulus of dough $\left(\mathrm{G}^{\prime}\right)$ at strain ranges of $0.04-36 \%$

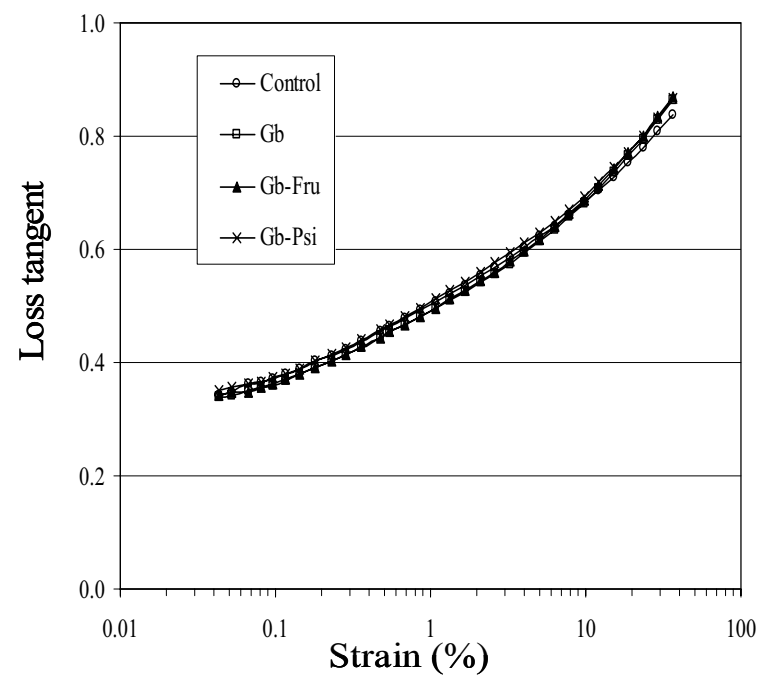

Figure 3-The effect of $\mathrm{Gb}$ and glycated $\mathrm{Gbs}$ on the loss tangent of dough at strain ranges of $0.04-36 \%$ 


\section{Literature Cited}

Aoki T, Hiidome Y, Kitahata K, Sugimoto Y, Ibrahim HR, Kato Y. 1999. Improvement of heat stability and emulsifying activity of ovalbumin by conjugation with glucoronic acid through the Maillard reaction. Food Research Int. 32:129-133.

Autio K, Kiesvaara M, Malkki Y, Kanko S. 1984. Chemical and functional properties of blood globin prepared by a new method. J. Food Sci. 49:859-863.

Autio K, Lyytikainen H, Malkki Y, Kanko S. 1985. Penetration studies of blood globin gels. J. Food Sci. 50:615-617.

Benjakul S, Lertittikul W, Bauer F. 2005. Antioxidant activity of Maillard reaction products from a porcine plasma protein-sugar model system. Food Chem. 93:189-196.

Dill CW, Landmann WA.1988. Food grade proteins from edible blood. In: Pearson AM, Dutson TR, ediors. Edible meat by-products, advances in meat research. $5^{\text {th }} \mathrm{V}$. Elsevier applied science: New York. p 127-145.

Duarte R, Carvalho SM, Sgarvieri V. 1999. Bovine blood components: fractionation, composition, and nutritive value. J. Agric. Food Chem. 47:231-236.

Gómez-Juárez C, Castellanos R, Ponce-Noyola T, Calderón-Salinas V, Figueroa JD. 1999. Functional properties of globin protein obtained from bovine blood by decolorisation of the red cell fraction. J. Sci. Food Agric. 79:793-796.

Hayakawa S, Matsuura Y, Nakamura R, Sato Y. 1986. Effect of heat treatment on preparation of colorless globin from bovine hemoglobin using soluble carboxymethyl cellulose. J. Food Sci. 51:786-790.

Hayakawa S, Ogawa T, Sato Y. 1982. Some functional properties under heating of the globin prepared by carboxymethyl cellulose procedure. J. Food Sci. 47:1415-1418.

Márquez E, Bracho M, Archile A, Rangel L, Benítez B. 2005. Proteins, isoleucine, lysine and methionine content of bovine, porcine and poultry blood and their fractions. Food Chem. 93:503-505.

Shahidi F, Naczk M, Rubin LJ, Diosady LL. 1984. Functional properties of blood globin. J. Food Sci. 49:370-372.

Sun Y, Hayakawa S, Izumori K. 2004. Antioxidative activity and gelling rheological properties of dried egg white glycated with a rare keto-hexose through the Maillard reaction. J. Food Sci. 69:427-434.

Sun Y, Hayakawa S, Izumori K. 2004. Modification of ovalbumin with a rare ketohexose through the Maillard reaction: effect on protein structure and gel properties. J. Agric Food Chem. 52:1293-1299.

Sun Y, Hayakawa S, Somwipa P, Izumori K. 2006. Chemical properties and antioxidative activity of glycated $\alpha$-lactalbumin with a rare sugar, D-allose, by Maillard reaction. Food Chem. 95:509-517.

Tybor PT, Dill CW, Landmann WA. 1975. Functional properties of proteins isolated from bovine blood by a continuous pilot process. J. Food Sci. 40:155-159.

Wismer-Perderson J. 1979. Utilization of animal blood in meat products. Food Technol. 33(8):76-80. 
Yilmaz Y, Toledo R. 2005. Antioxidant activity of water-soluble Maillard reaction products. Food Chem. 93:273-278. 